\title{
Reliability Estimation of Object-Oriented Software: Design Phase Perspective
}

\author{
Anil Kumar ${ }^{1}$, Namrata Dhanda ${ }^{2}$ \\ Scholar, Department of Computer Science, GITM, Lucknow, India ${ }^{1}$ \\ Associate Professor, Department of Computer Science, GITM, Lucknow, India ${ }^{2}$
}

\begin{abstract}
This paper does a wide-ranging review on object oriented software Reliability, and put forth some appropriate information about design level Reliability. Reliability has been recognized as a major factor to software quality, an importance is being drawn to measure reliability early in development life cycle. In this study a metrics based Reliability Estimation Model for object oriented design has been developed. A suit of design metrics useful in measuring Reliability of software has been identified. Developed model measures the reliability of object oriented design in terms of 'Effectiveness' and 'Functionality. The study shows a relationship among 'design properties with reliability key factors Effectiveness and Functionality in accordance with its anticipated weight and significance. Finally the developed model has been empirically validated and contextual interpretation has been drawn using industrial software projects.
\end{abstract}

Keywords: Reliability, Estimation, Software Quality, Design Phase

\section{INTRODUCTION}

In today's world, the significance of producing quality oriented software is no longer a beneficial but a required factor. Regrettably, the majority of the software companies not only fails to deliver quality software to their customers, but in addition does not recognize the appropriate quality attributes [3]. The development of quality oriented software still leftovers a matter of proper guidelines, finest practices and undocumented expert knowledge. In the highly competitive software industry, customer pressure causes Companies to go faster the speed to deliver software products [4]. Though Schedules are frequently tightly limited; developers are required to weigh the importance of software quality against the possibility of missing deadlines. For meeting the objective, 'on time delivery' testing time is normally reduced, which increases the prospective for defects, leading to problems with the final products.

This includes unfinished design, poor quality, high maintenance costs, and the risk of losing customer satisfaction. According to statistical information, more than $80 \%$ of all software delivered in the United States is not reviewed for defects, at a cost to the state economy of tens of billions of dollars each year [18]. Under these situations, software quality tends to suffer leading to severe consequences.

Software reliability is a key characteristic for software quality and is an essential factor to measure software failures [1]. Software Reliability is the property of referring 'how well software meets its specified requirements' and moreover 'the possibility of failure free operation for the particular period of time in a specified environment' [2].There are several mechanisms to makes the system more reliable [6]. Among several mechanisms object oriented design is one of the significant approach to measure reliability early in development life cycle. There is a common consensus among industry professionals and academicians in integrating Reliability within the development life cycle in order to deliver quality software. After the above conversation our conclusion is that Reliability is a quality factor [21].The goal of increasing the Reliability of software is not just to detect defects but more importantly, to detect defects as soon as they are initiated [22]. Therefore, reducing the price and overall time to fix the bug and producing higher quality reliable software each build of the release of development cycle.

\section{RELIABILITY CRITERIA}

Criteria are the characteristics which categorize the software quality factors. The criteria of the factors are the attributes of the software product by which the factor can be measured or characterized. Quality Criteria provide a more accurate and authentic definition of factors as well as common Criteria among factors facilitate to show the correlation among factors [12, 19]. Moreover design Criteria allow Estimation and review design metrics to be developed with greater acceptance and provide consent to recognize that area of software quality factors which may not be up to an acceptable standard [23]. After an exhaustive literature review it is appeared, Effectiveness and functionality are two of the most important reliability criteria [9].Its proper Estimation always support and help the designers to produce good quality reliable product within specified constraints.

\section{RELIABILITY CRITERIA}

Object oriented technology direct the designers and developers what to take and what to avoid from [20]. A Number of measures have been defined so far to assess 
object oriented design. There are a range of important themes of object oriented design that are recognized to be the basis of internal quality of object oriented software and help in the context of Estimation. These themes extensively take account of encapsulation, coupling, cohesion and inheritance $[14,16,17]$.

\begin{tabular}{|c|c|c|c|c|c|}
\hline \multicolumn{6}{|c|}{$\begin{array}{l}\text { Table1: OO Design Constructs Contributing in } \\
\text { Reliability Estimation At Design Phase: A } \\
\text { Critical Look }\end{array}$} \\
\hline $\begin{array}{l}\text { Design Parameters } \\
\qquad \rightarrow\end{array}$ & \multirow{2}{*}{$\begin{array}{l}\frac{0}{0} \\
\frac{0}{0} \\
\stackrel{0}{0}\end{array}$} & \multirow{2}{*}{ نْ } & \multirow{2}{*}{ 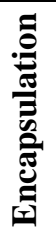 } & \multirow{2}{*}{ 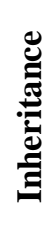 } & \multirow{2}{*}{ 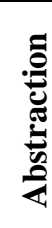 } \\
\hline Author/Study $\downarrow$ & & & & & \\
\hline $\begin{array}{l}\text { MC Gregor et al. } \\
\text { (1996) }\end{array}$ & & & $\sqrt{ }$ & $\sqrt{ }$ & \\
\hline Bruce \& Shi(1998) & & $\sqrt{ }$ & & $\sqrt{ }$ & \\
\hline B.Pettichord(2002) & & $\sqrt{ }$ & & & $\sqrt{ }$ \\
\hline Baidry et al.(2002) & & $\sqrt{ }$ & & & \\
\hline M Bruntik (2004) & & & $\sqrt{ }$ & $\sqrt{ }$ & \\
\hline $\begin{array}{l}\text { S.Mouchawrab } \\
\text { (2005) }\end{array}$ & $\sqrt{ }$ & $\sqrt{ }$ & & $\sqrt{ }$ & $\sqrt{ }$ \\
\hline $\begin{array}{l}\text { I.Ahson et } \\
\text { al.(2007) }\end{array}$ & $\sqrt{ }$ & $\sqrt{ }$ & & $\sqrt{ }$ & \\
\hline Nazir et al.(205) & $\sqrt{ }$ & $\sqrt{ }$ & & $\sqrt{ }$ & \\
\hline $\begin{array}{l}\text { Abdullah et al.( } \\
\text { (2014) }\end{array}$ & $\sqrt{ }$ & $\sqrt{ }$ & $\sqrt{ }$ & $\sqrt{ }$ & \\
\hline Khan et al. (2012) & $\sqrt{ }$ & $\sqrt{ }$ & $\sqrt{ }$ & $\sqrt{ }$ & \\
\hline $\begin{array}{l}\text { Nikfard } \\
\text { \&Babak(2013) }\end{array}$ & & $\sqrt{ }$ & $\sqrt{ }$ & $\sqrt{ }$ & \\
\hline
\end{tabular}

\section{MODEL DEVELOPMENT}

The generic quality model $[11,19]$ has been considered as a basis to develop the Reliability Estimation model for object oriented design.

Quantification of design diagram Effectiveness and Functionality is precondition for the Reliability Estimation Model. For that reason before developing reliability model, the research paper has developed 2 models for Effectiveness and Functionality. In order to develop all the models given below multivariate linear model has applied $[11,13]$

$$
\mathrm{Y}=\mu+\beta_{1} * \mathrm{X}_{1}+\beta_{2} * \mathrm{X}_{2}+\ldots \ldots+\beta_{\mathrm{n}}^{*} \mathrm{X}_{\mathrm{n}}+\varepsilon
$$

\section{EFFECTIVENESS ESTIMATION MODEL}

Effectiveness is strongly related to reliability and regularly plays a key role to deliver high class, best quality reliable software within time and given budget [15]. It is one of the most important notions in design for testing of software programs and components [3]. In order to produce.

A multivariate model for Effectiveness of class diagram, metrics listed in [10], will play the responsibility of independent variables whereas Effectiveness will be in use as dependent variable. The required data used for developing Effectiveness Estimation model is taken from [10]. The correlation in the middle of reliability factors and object oriented characteristics has been established as depicted in equation 2.Using SPSS, values of coefficient are calculated and Effectiveness model is formulated as given below:

Effectiveness $=-\mathbf{4 . 5 5 9}+\mathbf{2 . 5 5 7} \times$ Encapsulation $+.738 \times$ Coupling $+5.353 \times$ Inheritance (2)

\begin{tabular}{|c|c|c|c|c|c|c|c|c|}
\hline \multicolumn{9}{|c|}{ Table2:Coefficients ${ }^{2}$} \\
\hline & \multirow{2}{*}{ Model } & \multicolumn{2}{|c|}{$\frac{\text { Unstandardized }}{\text { Coefficients }}$} & \multirow{2}{*}{\begin{tabular}{|c|}
$\begin{array}{c}\text { Standardized } \\
\text { Coefficients }\end{array}$ \\
Beta
\end{tabular}} & \multirow{2}{*}{$t$} & \multirow{2}{*}{ Sig. } & \multicolumn{2}{|c|}{$\begin{array}{l}95.0 \% \text { Confidence } \\
\text { Interval for B }\end{array}$} \\
\hline & & B & $\begin{array}{l}\text { Std. } \\
\text { Error }\end{array}$ & & & & $\begin{array}{l}\text { Lower } \\
\text { Bound }\end{array}$ & $\begin{array}{l}\text { Upper } \\
\text { Bound }\end{array}$ \\
\hline \multirow{4}{*}{1} & (Constant) & -4.559 & 5.917 & & -.770 & .522 & -30.019 & 20.901 \\
\hline & Encapsulation & 2.557 & 8.129 & .082 & .315 & .783 & -32.419 & 37.533 \\
\hline & Coupling & .738 & .229 & .876 & 3.225 & .084 & -.246 & 1.723 \\
\hline & Inheritance & 5.353 & 2.442 & .358 & 2.192 & .160 & -5.154 & 15.859 \\
\hline & & & & & & & & \\
\hline
\end{tabular}

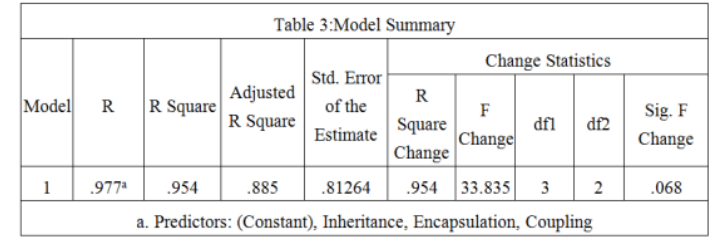

\begin{tabular}{|c|c|c|c|c|c|c|}
\hline \multicolumn{7}{|c|}{ Table 4:ANOVA $^{\text {b }}$} \\
\hline \multirow{2}{*}{ Model } & Sum of Squares & df & $\begin{array}{c}\text { Mean } \\
\text { Square }\end{array}$ & F & Sig. \\
\hline \multirow{3}{*}{1} & Regression & 27.410 & 3 & 9.137 & 33.835 & $.068^{\mathrm{a}}$ \\
\hline & Residual & 1.321 & 2 & .660 & & \\
\cline { 2 - 7 } & Total & 28.731 & 5 & & & \\
\cline { 2 - 7 } & a. Predictors: (Constant), Inheritance, Encapsulation, Coupling \\
\hline \multicolumn{7}{|c|}{ b. Dependent Variable: Effectiveness } \\
\hline
\end{tabular}

VI. FUNCTIONALITY ESTIMATION MODEL

The responsibilities assigned to the classes of a design, which are made available by the classes through their public interfaces. This refers to a design's ability to achieve the desired functionality and behavior using object oriented design concept and techniques. In order to produce a multivariate model for functionality of class diagram, metrics listed in [10], will play the responsibility of independent variables whereas functionality will be in use as dependent variable. The required data used for developing functionality Estimation model is taken from [10]. The correlation in the middle of reliability factors and object oriented characteristics has been established as depicted in equation 3.Using SPSS, values of coefficient are calculated and Effectiveness model is formulated as given below:

Functionality $=1.656+1.141 \times$ Coupling $+13.336 \times$ Cohesion $+-1.043 \times$ Inheritance

\begin{tabular}{|c|c|c|c|c|c|c|c|c|}
\hline \multicolumn{9}{|c|}{ Table 5 :Coefficients ${ }^{2}$} \\
\hline & \multirow{2}{*}{ Model } & \multicolumn{2}{|c|}{$\frac{\text { Unstandardized }}{\text { Coefficients }}$} & \multirow{2}{*}{$\begin{array}{c}\begin{array}{r}\text { Standardized } \\
\text { Coefficients }\end{array} \\
\text { Beta } \\
\end{array}$} & \multirow[t]{2}{*}{$\mathrm{t}$} & \multirow{2}{*}{ Sig. } & \multicolumn{2}{|c|}{$\begin{array}{l}95.0 \% \text { Confidence Interval } \\
\text { for B }\end{array}$} \\
\hline & & $\mathrm{B} \mid$ & Std. Error & & & & \begin{tabular}{|l|} 
Lower Bound \\
\end{tabular} & Upper Bound \\
\hline \multirow{4}{*}{1} & (Constant) & 1.656 & 3.752 & & .441 & .702 & -14.489 & 17.802 \\
\hline & Coupling & 1.141 & 1.247 & .472 & .915 & .457 & -4.224 & 6.507 \\
\hline & Cohesion & 13.336 & 6.694 & 1.095 & 1.992 & .185 & -15.466 & 42.137 \\
\hline & Inheritance & -1.043 & .751 & -.701 & -1.388 & .300 & -4.276 & 2.190 \\
\hline \multicolumn{9}{|c|}{ a. Dependent Variable: Functionality } \\
\hline
\end{tabular}


International Journal of Advanced Research in Computer and Communication Engineering Vol. 4, Issue 3, March 2015

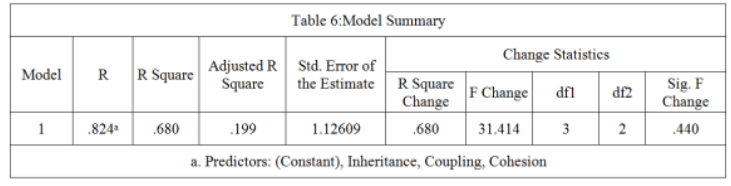

Reliability $=1.384-.284 \times$ Effectiveness $-.096 \times$ Functionality

(4)

\begin{tabular}{|c|c|c|c|c|c|c|}
\hline \multicolumn{7}{|c|}{ Table 7:ANOVA } \\
\hline \multirow{2}{*}{ Model } & $\begin{array}{c}\text { Sum of } \\
\text { Squares }\end{array}$ & df & $\begin{array}{c}\text { Mean } \\
\text { Square }\end{array}$ & F & Sig. \\
\hline \multirow{3}{*}{1} & Regression & 5.379 & 3 & 1.793 & 31.414 & $.440^{\mathrm{a}}$ \\
\cline { 2 - 7 } & Residual & 2.536 & 2 & 1.268 & & \\
\cline { 2 - 7 } & Total & 7.915 & 5 & & & \\
\hline \multicolumn{7}{|c|}{ a. Predictors: (Constant), Inheritance, Coupling, Cohesion } \\
\hline \multicolumn{6}{|c|}{ b. Dependent Variable: Functionality } \\
\hline
\end{tabular}

\section{RELIABILITY MODEL}

Before developing the model for Reliability, it is important to make sure the appropriate association among Reliability, Effectiveness and Functionality of class diagrams. Table 8 , shows the relationship values among them. From the correlation values it is clear that both Effectiveness and Functionality are strongly correlated with Reliability [10].

\begin{tabular}{|c|c|c|c|c|}
\hline \multicolumn{5}{|c|}{ Table 8:Correlations } \\
\hline & & Reliability & Effectiveness & Functionality \\
\hline \multirow{3}{*}{$\begin{array}{c}\text { Pearson } \\
\text { Correlation }\end{array}$} & Reliability & 1.000 & .439 & .721 \\
\cline { 2 - 5 } & Effectiveness & .439 & 1.000 & .917 \\
\cline { 2 - 5 } & Functionality & .721 & .917 & 1.000 \\
\hline
\end{tabular}
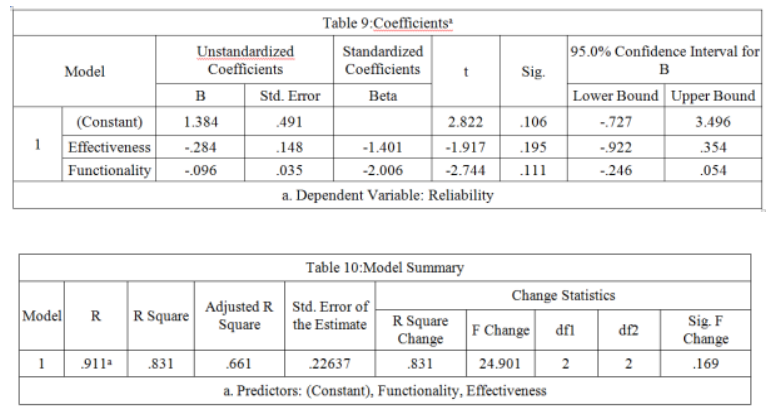

\begin{tabular}{|c|c|c|c|c|c|c|}
\hline \multicolumn{7}{|c|}{ Table 11:ANOVA } \\
\hline \multicolumn{2}{|r|}{ Model } & Sum of Squares & df & $\begin{array}{l}\text { Mean } \\
\text { Square }\end{array}$ & $\mathrm{F}$ & Sig. \\
\hline \multirow{3}{*}{1} & Regression & .502 & 2 & .251 & 24.901 & $.169^{\mathrm{a}}$ \\
\hline & Residual & .102 & 2 & .051 & & \\
\hline & Total & .605 & 4 & & & \\
\hline \multicolumn{7}{|c|}{ a. Predictors: (Constant), Functionality, Effectiveness } \\
\hline \multicolumn{7}{|c|}{ b. Dependent Variable: Reliability } \\
\hline
\end{tabular}

\section{EMPIRICAL VALIDATION}

Empirical Validation is an essential part of proposed research. Empirical Validation is the standard approach to give good reason for the model approval. Taking view of this reality, practical validation fo the reliability model has been performed using sample tryouts. In order to validate developed reliability model the data has been taken from[19]

\begin{tabular}{|c|c|c|c|c|c|}
\hline \multirow{2}{*}{ Projects } & \multicolumn{2}{|c|}{$\begin{array}{c}\text { Reliability } \\
\text { Ranking }\end{array}$} & \multirow{2}{*}{$\sum \mathrm{d}^{2}$} & \multirow[b]{2}{*}{$r_{s}$} & \multirow[b]{2}{*}{$\mathrm{r}_{3}> \pm .781$} \\
\hline & $\begin{array}{l}\text { Computed } \\
\text { Rank }\end{array}$ & $\begin{array}{l}\text { Actual } \\
\text { Rank }\end{array}$ & & & \\
\hline P1 & 5 & 2 & 9 & 0.945455 & $\checkmark$ \\
\hline $\mathrm{P} 2$ & 7 & 5 & 4 & 0.975758 & $\checkmark$ \\
\hline P3 & 3 & 1 & 4 & 0.975758 & $\checkmark$ \\
\hline P4 & 8 & 6 & 4 & 0.975758 & $\checkmark$ \\
\hline P5 & 9 & 9 & 0 & 1.000000 & $\checkmark$ \\
\hline P6 & 4 & 3 & 1 & 0.993939 & $\checkmark$ \\
\hline P7 & 6 & 7 & 1 & 0.993939 & $\checkmark$ \\
\hline P8 & 2 & 4 & 4 & 0.975758 & $\checkmark$ \\
\hline P9 & 1 & 8 & 49 & 0.70303 & $x$ \\
\hline P10 & 10 & 10 & 0 & 1.00000 & $\checkmark$ \\
\hline
\end{tabular}

Speraman's Coefficient of Correlation $\boldsymbol{r}_{\boldsymbol{s}}$ was used to verify the importance of correlation among calculated values of reliability using model and it's 'Known Values'. The ' $r s$ ' was estimated using the technique given as under: Speraman's Coefficient of Correlation

$$
r_{s}=1-\frac{6 \sum d^{2}}{n\left(n^{2}-1\right)} \quad-1.0 \leq r_{s} \leq+1.0
$$

' $\mathrm{d}$ ' = difference between 'Calculated ranking' and 'Known ranking' of reliability.

$\mathrm{n}=$ number of projects $(\mathrm{n}=10)$ used in the experiment.

The correlation values amid reliability through model and known rating are shown in table (11) above. Pairs of these values with correlation values $\boldsymbol{r}_{\boldsymbol{s}}$ above [ \pm .781 ] are checked in table. The correlations are up to standard by high degree of confidence, i.e. up to $99 \%$. Therefore we can conclude without any loss of generality that reliability Estimation model measures are really reliable and considerable and relevant.

\section{CONCLUSION}

The research study has developed three models namely Effectiveness Estimation Model, Functionality Estimation Model and finally Reliability Estimation Model for object oriented design., Reliability Estimation Model measures the, Reliability of design class diagrams in respect of their Effectiveness and Functionality. The paper additionally validates the quantifying ability of Reliability Estimation Model. Beside these, a reliability index can also be developed that may help other researchers in measuring reliability of object oriented design. 


\section{REFERENCES}

[1] Zainab Al-Rahamneh, Mohammad Reyalat, Alaa F. Sheta, Sulieman Bani-Ahmad, Saleh Al-Oqeili," "A New Software Reliability Growth Model: Genetic-Programming-Based Approach", Journal of Software Engineering and Applications, 2011, Vol: 4, PP:476-481 doi:10.4236/jsea.2011.48054..

[2] Natasha Sharygina , James C. Browne, and Robert P. Kurshan, "A Formal Object-Oriented Analysis for Software Reliability: Design for Verification", 2011, pp:1-15

[3] Abdullah, Dr, Reena Srivastava, and M. H. Khan."Modifiability: A Key Factor To Testability", International Journal of Advanced Information Science and Technology, Vol. 26, No.26, Pages 62-71 June 2014.

[4] Nikolaos Tsantalis, Alexander Chatzigeorgiou, "Predicting the Probability of Change in Object-Oriented Systems", IEEE Transactions on Software Engineering, VOL. 31, NO. 7, July 2005, pp: 601-614.

[5] Stephanie Gaudan, Gilles Motet and Guillaume Auriol , "A new structural complexity metrics applied to Object Oriented design reliability assessment", http://www.lesia.insatoulouse.fr/ motet/papers/2007_ISSRE_GMA.pdf.

[6] Mahfuzul Huda, Dr.Y.D.S.Arya, and Dr.M. H. Khan. "Measuring Testability of Object Oriented Design: A Systematic Review." International Journal of Scientific Engineering and Technology, Vol. 3, Issue 10, pp: 1313-1319 Oct, 2014.

[7] Everald E. Mills, "Software Metrics", SEI Curriculum Module SEICM-12-1.1, Software Engineering Institute, Dec 1988, pp: 1-43.

[8] Haifeng Li Minyan Lu Qiuying Li , "Software Reliability Metrics Selecting Method Based on Analytic Hierarchy Process", Sixth International Conference on Quality Software, 2006. QSIC 2006, 27-28 Oct. 2006 , pp: 337 - 346, ISSN: 1550-6002, ISBN: 0-76952718-3.

[9] Offutt, J. and R. Alexander, (2001): A fault Model for Subtype Inheritance and Polymorphism. In 12th International Symposium, Software Reliability Engineering, Nov 27-30, 2001, IEEE, pp. 8493.

[10] Jagdish Bansiya, "A Hierarchical Model for Object Oriented Design Quality Assessment", IEEE Transaction of Software Engineering, Volume 28, No. 1, January 2002, and pp: 4-17

[11] Abdullah, Dr, M. H. Khan, and Reena Srivastava. "Testability Estimation Model for Object Oriented Design $\left(\mathrm{TMM}^{\mathrm{OOD}}\right)$." International Journal of Computer Science \& Information Technology (IJCSIT) Vol. 7, No 1, February 2015, DOI: 10.5121/ijcsit.2015.7115.

[12] F. Li., T.Yi, "Apply Page Rank Algorithm to Measuring Relationship's Complexity", IEEE, DOI 10.1109/ PACIIA.2008.309, pp. 914-917, 2008, ISBN: 9780769534909.

[13] Abdullah, Dr, Reena Srivastava, and M. H. Khan. "Testability Estimation Framework: Design Phase Perspective."International Journal of Advanced Research in Computer and Communication Engineering Vol. 3, Issue 11, Pages 8573-8576 November 2014.

[14] Yong Cao Qingxin Zhu. Improved metrics for encapsulation based on information hiding. DOI: 10.1109/ICYCS.2008.76, The 9th International Conference for Young Computer Scientists, IEEE computer society 2008, p: 742-724.

[15] Mahfuzul Huda, Dr.Y.D.S.Arya, and Dr. M. H. Khan. "Evaluating Effectiveness Factor of Object Oriented Design: A Testability Perspective." International Journal of Software Engineering \& Applications (IJSEA), Vol.6, No.1, January 2015, DOI:10.5121/ijsea.2015.6104.

[16] Sch aril N., Black Andrew P., Ducasse S. Object oriented Encapsulation for Dynamically Typed Languages. OOPSLA 2004, ACM, pp: 130-139.

[17] Abdullah, Dr, Reena Srivastava, and M. H. Khan. "Testability Estimation of Object Oriented Design: A Revisit". International Journal of Advanced Research in Computer and Communication Engineering Vol. 2, Issue 8, pages 3086-3090, August 2013.

[18] Usha Chhillar, Shuchita Bhasin , " A New Weighted Composite Complexity Measure for Object-Oriented Systems", International Journal of Information and Communication Technology Research Volume 1 No. 3, July 2011,pp: 101-108, ISSN-2223-4985.

[19] Dromey, R.G.: A Model for Software Product Quality. IEEE Transaction on Software Engineering 21(2), 146-162 (1995).

[20] Abdullah, Dr, M. H. Khan, and Reena Srivastava. "Flexibility: A Key Factor To Testability", International Journal of Software
Engineering \& Applications (IJSEA), Vol.6, No.1, January 2015. DOI: $10.5121 /$ ijsea.2015.6108.

21] Fiondella, L.; Gokhale, S.S., "Software reliability model with bathtub-shaped fault detection rate" Reliability and Maintainability Symposium (RAMS), 2011 Proceedings - Annual , 24-27 Jan. 2011,pp: 1 - 6, ISBN: 978-1-4244-8857-5.

[22] Mahfuzul Huda, Dr.Y.D.S.Arya, and Dr. M. H. Khan. "Testability Quantification Framework of Object Oriented Software: A New Perspective." International Journal of Advanced Research in Computer and Communication Engineering, Vol. 4, Issue 1, Jan, 2015, DOI: 10.17148/IJARCCE.2015.4168

[23] Mohan, K.K.; Verma, A.K.; Srividya, A., "Software reliability estimation through black box and white box testing at prototype level ", 2nd International Conference on Reliability, Safety and Hazard (ICRESH), 14-16 Dec. 2010, pp: 517 - 522, ISBN: 978-14244-8344-0. 